\title{
Crystal Structures of Cobalt-Exchanged Sodium GTS-type Titanosilicates and the Elution Test by Acid Solution
}

\author{
K. Fujiwara, T. Tamaki, C. Kishimori, R. Titorenkova, A. Nakatsuka, N. Nakayama \\ Graduate School of Science and Engineering, Yamaguchi Univ., 2-16-1, Tokiwadai, Ube, Yamaguchi, Japan \\ Fax: 81-836-85-9201, e-mail: keiko@yamaguchi-u.ac.jp
}

\begin{abstract}
Fine particles of Na-GTS have been prepared by using hydrothermal method. $\mathrm{Co}^{2+}$-exchanged GTS were obtained by shaking $0.5 \mathrm{~g}$ of the single-phase Na-GTS sample in the aqueous solutions of $\mathrm{CoCl}_{2}(25 \mathrm{~mL}, 0.025 \sim 1.0 \mathrm{M})$ at $40^{\circ} \mathrm{C}$ for 24 hours. Samples with the composition $0.23 \leq x \leq 0.9$ in the formula of $\mathrm{Na}_{4-4 x} \mathrm{Co}_{2 x} \mathrm{Ti}_{4} \mathrm{Si}_{3} \mathrm{O}_{16}$ were obtained. With the increase of Co composition $x$, the rhombohedral lattice parameter $a$ increases and $\alpha$ becomes close to $90^{\circ}$. The Co elution ratios were about $90 \%$ for the samples with $x=0.23$ and 0.56 , whereas $70 \%$ for the samples of ion exchange ratio with $x=0.88$. By $\mathrm{Co}^{2+}$ exchange, the water content increased from 20.5 to $24.5 \%$ and the DTA peak temperature due to the dehydration was lowered from 253 to $230^{\circ} \mathrm{C}$. FT-IR spectra showed apparent change in the absorption peaks due to the $\mathrm{O}-\mathrm{H}$ stretching in the range of $3000 \sim 3600 \mathrm{~cm}^{-1}$ suggesting some change in the hydration state.
\end{abstract}

Key words: Microporous crystal, TG-DTA, XRD, Co-exchanged, Dehydration

\section{INTRODUCTION}

GTS-type titanosilicates $\mathrm{A}_{x} \mathrm{Ti}_{4} \mathrm{Si}_{3} \mathrm{O}_{16} \cdot y \mathrm{H}_{2} \mathrm{O}(\mathrm{A}: \mathrm{H}$, $\mathrm{Na}, \mathrm{K}, \mathrm{Cs})$ have a 3-dimensional tunnel-type microporous structure [1-4]. Its framework structure consists of $\mathrm{SiO}_{4}$ tetrahedra and $\mathrm{Ti}_{4} \mathrm{O}_{16}$ clusters made of four edge sharing $\mathrm{TiO}_{6}$ octahedra. They are linked by corner sharing to form a three-dimensional pore system of 8-ring channels, occupied by the alkali-metal ions and adsorbed water molecules [1]. The crystal structure of Na-GTS $\left(\mathrm{Na}_{4} \mathrm{Ti}_{4} \mathrm{Si}_{3} \mathrm{O}_{16} \cdot 6 \mathrm{H}_{2} \mathrm{O}\right)$ shows rhombohedral symmetry $\left(R \overline{3} m, a=7.812 \AA, \alpha=88.79^{\circ}\right)$ [1]. It is interesting to investigate the cobalt ion exchange properties of Na-GTS for the application of GTS to the removal of radioactive Co isotopes from the waste water. Although the ion exchange properties of GTS for divalent cations $\left(\mathrm{Co}^{2+}, \mathrm{Ca}^{2+}, \mathrm{Sr}^{2+}, \mathrm{Ba}^{2+}\right.$, etc. $)$ have been published $[4,5,6]$, the details of the crystal structures have not been reported. In this study, the compositional dependence of crystal structures and the elution test by acid solution for $\mathrm{Co}^{2+}$-exchanged $\mathrm{Na}-\mathrm{GTS}$. We have prepared series of samples with the different compositions $x$ in $\mathrm{Na}_{4-4 x} \mathrm{Co}_{2 x} \mathrm{Ti}_{4} \mathrm{Si}_{3} \mathrm{O}_{16} \cdot y \mathrm{H}_{2} \mathrm{O}$. The crystal structure and dehydration behavior were examined by powder XRD, TEM, TG-DTA, FT-IR and Raman. The elution test by acid solution was also performed.

\section{EXPERIMENTAL}

2.1 Sample preparation

GTS-type sodium titanosilicates (Na-GTS: $\mathrm{Na}_{4} \mathrm{Ti}_{4} \mathrm{Si}_{3} \mathrm{O}_{16} \cdot 6 \mathrm{H}_{2} \mathrm{O}$ ) were prepared by hydrothermal method according to the procedure reported by Kostov-Kytin et al. [7, 8]. The starting materials are $\mathrm{NaOH}$, amorphous $\mathrm{SiO}_{2}$ fine powder and aqueous solution of $\mathrm{TiCl}_{4}$ and $\mathrm{HCl}$. The mixtures with the compositional ratio of $\mathrm{TiO}_{2} / \mathrm{SiO}_{2}=0.32$ and $\mathrm{Na}_{2} \mathrm{O} / \mathrm{TiO}_{2}$ $=5.62$ were heat-treated at $100^{\circ} \mathrm{C}$ for 24 hour in a closed pressure-resistant vessel. The samples obtained were filtered with distilled water and dried at $40^{\circ} \mathrm{C}$ for $48 \mathrm{~h}$. The $\mathrm{Co}^{2+}$-exchanged GTS samples were obtained by shaking $0.5 \mathrm{~g}$ of Na-GTS in the aqueous solutions of $\mathrm{CoCl}_{2}(25 \mathrm{~mL})$ at room temperature for 24 hour. The concentration of $\mathrm{CoCl}_{2}$ solution $\left(C_{\mathrm{Co}}\right)$ was varied in the range from 0.025 to $1.0 \mathrm{M}$. The amount of $\mathrm{Na}^{+}$ions in the $0.50 \mathrm{~g}$ of GTS is $2.7 \times 10^{-3} \mathrm{~mol}$. The equivalent amount of $\mathrm{Co}^{2+}\left(1.35 \times 10^{-3} \mathrm{~mol}\right.$, considering the ionic charge) is included in the $25 \mathrm{~mL}$ of $0.054 \mathrm{M}$ $\mathrm{CoCl}_{2}$ solution.

For the elution test, Co-exchanged samples $(0.5 \mathrm{~g}$, $C_{\mathrm{Co}}=0.025,0.1$ and $0.5 \mathrm{M}$ ) were shaken in $0.1 \mathrm{M} \mathrm{HNO}_{3}$ $(25 \mathrm{~mL})$ at $40^{\circ} \mathrm{C}$ for 24 hour. The samples obtained were filtrated, washed, and dried at $40^{\circ} \mathrm{C}$.

\subsection{Characterization}

The Co concentration in the supernatant solutions was analyzed with EDTA titration [9] and atomic absorption spectrometry (AAS) to evaluate the ion-exchange amount. The actual composition of the precipitation was analyzed by the TEM-EDX for typical samples. The phase identification, the analyses of particle shape and size were performed by powder XRD and transmission electron microscopy (TEM), using a RIGAKU RINT2200 powder x-ray diffractometer and a JEOL JEM2010F transmission electron microscope (TEM). The dehydration process was examined by TG-DTA. The heating rate of $10^{\circ} \mathrm{C} / \mathrm{min}$ and the cooling rate of $20^{\circ} \mathrm{C} / \mathrm{min}$ were employed. For FT-IR and Raman measurements, HORIBA FT-730 and JASCO NRS-3000 spectrometers were used, respectively. 


\section{RESULTS and DISCUSSION}

\subsection{Co exchange amount}

Figure 1(a) and (b) show a TEM image and the corresponding electron diffraction (ED) pattern of a GTS sample shaken in $0.5 \mathrm{M} \mathrm{CoCl}_{2}$-aq. solution $\left(C_{\mathrm{Co}}\right.$ $=0.5$ ). The ring-type ED pattern and the image indicate that the samples are composed of polycrystalline fine particles with mean size of about $20 \mathrm{~nm}$. Figure 1(c) shows the EDX spectrum of a particle in Fig. 1(a). The $\mathrm{Co} / \mathrm{Ti}$ atomic ratio evaluated from the peak intensity ratio of $\mathrm{Co}-\mathrm{K}$ and $\mathrm{Ti}-\mathrm{K}$ lines is $x=0.85$ in $\mathrm{Na}_{4-4 x} \mathrm{Co}_{2 x} \mathrm{Ti}_{4} \mathrm{Si}_{3} \mathrm{O}_{16}$. The cobalt composition evaluated from EDTA titration of $\mathrm{Co}^{2+}$ ions in the filtrate after the ion exchange experiment was $x=0.88$ and that from AAS was 0.86 . These values well agree with each other. For other samples, the Co composition was estimated from EDTA titration as shown in Fig. 1(d). Samples with the composition $\mathrm{Na}_{4-4 x} \mathrm{Co}_{2 x} \mathrm{Ti}_{4} \mathrm{Si}_{3} \mathrm{O}_{16}(0.23 \leq x \leq$ $0.9)$ were obtained. The Co composition $x$ increases almost linearly with the increase of the logarithmic concentration of $\mathrm{CoCl}_{2}$ solution, $\log _{10} C_{\mathrm{Co}}$.

\subsection{XRD patterns}

Observed XRD patterns were shown in Fig. 2(a). With increasing the concentration of $\mathrm{CoCl}_{2}$-aq. solutions, they show the narrowing of peak width, peak shifts to the lower $2 \theta$ side and some change in the peak intensities. The peak width (FWHM) of the pseudo cubic 211 peak decreases from 0.86 to $0.51^{\circ}$. Its peak position shifts from $2 \theta=27.92$ to $27.71^{\circ}$. The lattice parameters and peak intensities were evaluated by a profile fitting method assuming rhombohedral unit cell.

Rhombohedral lattice parameters were shown in Fig. 2 (b). The lattice parameter $a$ increases with increasing of the Co composition $x$, almost linearly to the value of $\log _{10} C_{\mathrm{Co}}$. The lattice parameter $\alpha$ becomes close to $90^{\circ}$ with increasing of the Co composition $x$. For $\log _{10} C_{\mathrm{Co}}$ $\geq 0.1, \alpha$ is almost independent on $\log _{10} C_{\mathrm{Co}}$.
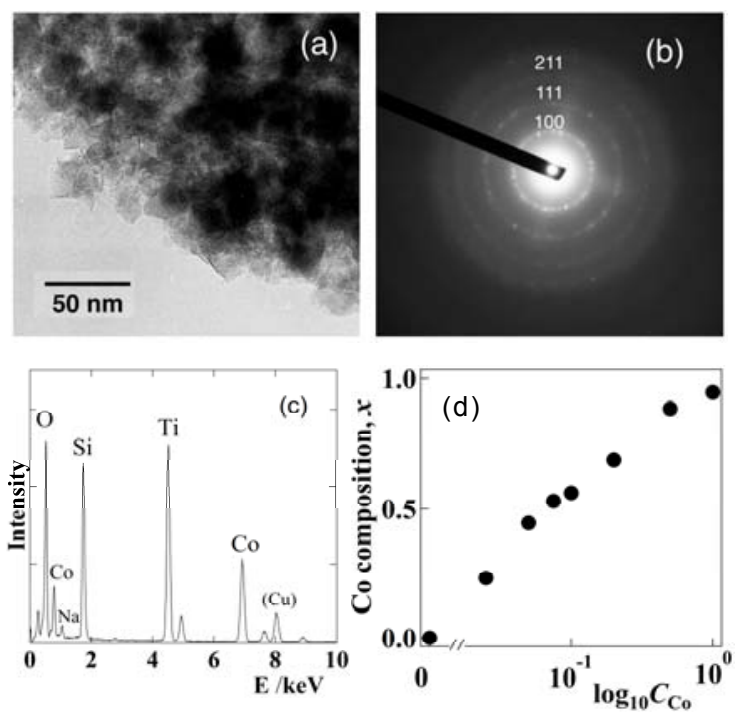

Fig. 1 TEM image and Composition of the sample shaken in $0.5 \mathrm{M} \mathrm{CoCl}_{2}$ solution. A bright field TEM image, (a) an ED pattern, (b) an EDX spectrum, and (c) Co composition $x$ in $\mathrm{Na}_{4-4 x} \mathrm{Co}_{2 x} \mathrm{Ti}_{4} \mathrm{Si}_{3} \mathrm{O}_{16}$ evaluated from the EDTA titration of Co in the filtrate after the ion exchange experiment (d).
It is suggested that the lattice system is well assumed to be cubic. Lattice parameters of the sample treated with $0.5 \mathrm{M} \mathrm{CoCl}_{2}$-aq. solutions were $a=7.855(5) \AA$ and $\alpha=$ $89.60(3)^{\circ}$, whereas those for the pristine Na-GTS were $a$ $=7.819(1) \AA$ and $\alpha=89.00(2)^{\circ}$.

Figure 3 shows the composition dependence of XRD integrated peak intensity. The integrated intensity of pseudo-cubic $h k l$ peak, $I(h k l)$, was normalized by the integrated intensity $I(211)$ of pseudo-cubic 211 peak $(211,2 \overline{1} 1$, and $2 \overline{11}$ peaks of rhombohedral system).

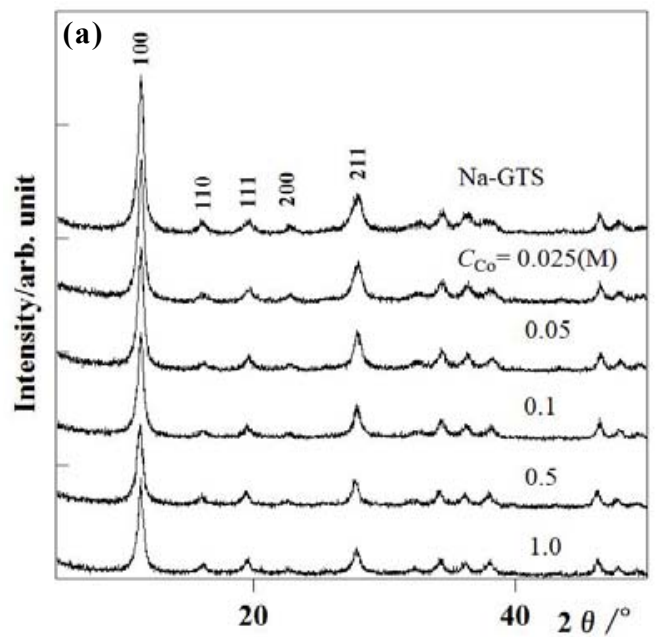

(b)
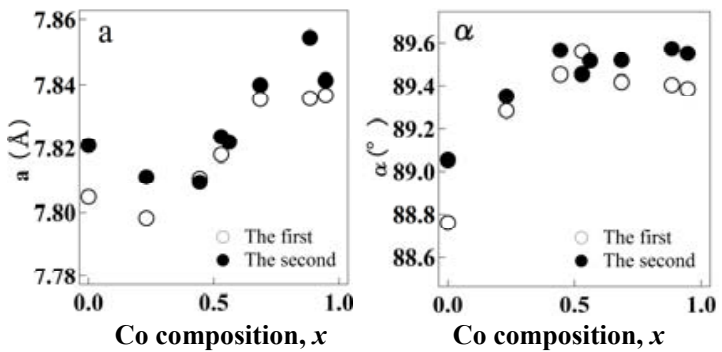

(c) $I(\mathrm{hkl}) / \mathrm{I}(211)$

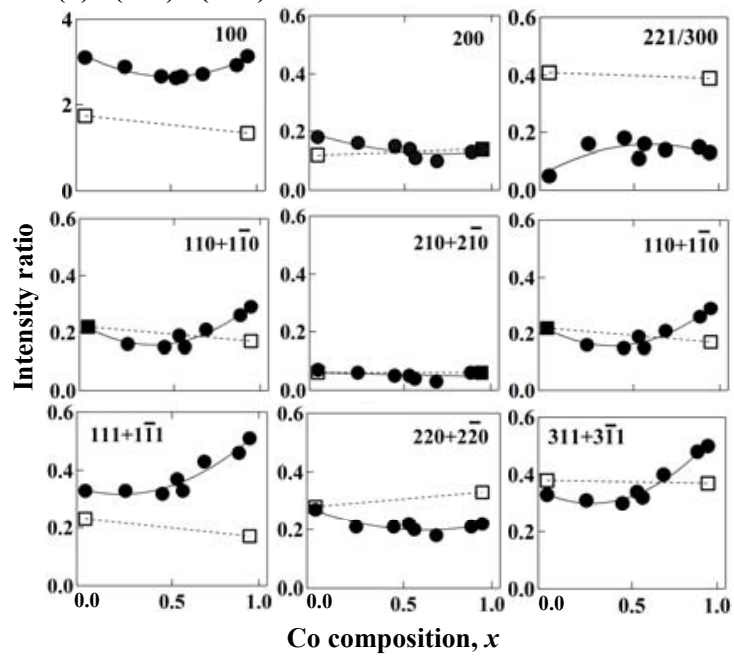

Fig. 2 Observed XRD patterns (a), rhombohedral lattice parameters (b), and the peak intensities (c). In (b) and (c), the horizontal axis shows Co composition $x$ in $\mathrm{Na}_{4-4 x} \mathrm{Co}_{2 x} \mathrm{Ti}_{4} \mathrm{Si}_{3} \mathrm{O}_{16}$. The marks $\square$ show calculated intensity ratios for rhombohedral $\mathrm{Na}_{4} \mathrm{Ti}_{4} \mathrm{Si}_{3} \mathrm{O}_{16} \cdot 6 \mathrm{H}_{2} \mathrm{O}$ and $\mathrm{Co}_{2} \mathrm{Ti}_{4} \mathrm{Si}_{3} \mathrm{O}_{16} \cdot 6 \mathrm{H}_{2} \mathrm{O}$. 
The intensity ratios $I(h k l) / I(211)$ of pseudo-cubic 110 , 111, and 311 peaks show apparent increase with increasing of Co composition $x$. To reproduce the observed variation of peak intensity, XRD profiles were calculated for several model structures.

In the first model (Model 1), Co atoms were placed in Na sites: $3 a$ site at $(0.910,0.444,0.444)$ and $1 a$ site at $(x$, $x, x) ; x=0.653$, keeping other atomic positions of rhombohedral Na-GTS $\left(\mathrm{Na}_{4} \mathrm{Ti}_{4} \mathrm{Si}_{3} \mathrm{O}_{16} \cdot 6 \mathrm{H}_{2} \mathrm{O}\right)$ [1]. Taking the charge balance, the occupancies of $\mathrm{Co}$ atoms are set to be 0.5 and the composition is $\mathrm{Co}_{2} \mathrm{Ti}_{4} \mathrm{Si}_{3} \mathrm{O}_{16} \cdot 6 \mathrm{H}_{2} \mathrm{O}$. The calculated profile is shown in Fig. 3 compared with the observed profile for the Co exchanged sample treated in the solution with $C_{\mathrm{Co}}=$ $0.5 \mathrm{M}(\mathrm{x}=0.9)$. The observed peak intensities cannot be reproduced by the simple exchange of $\mathrm{Na}$ with $\mathrm{Co}$, although intensity enhancement of pseudo-cubic 110 and 111 peaks are almost reproduced.

The second model (Model 2) is based on the cubic $P 43 m$ structure of K-GTS $\left(\mathrm{K}_{3} \mathrm{HTi}_{4} \mathrm{Si}_{3} \mathrm{O}_{16} \cdot 4 \mathrm{H}_{2} \mathrm{O}\right)$ [3]. Co atoms are placed at the $\mathrm{K}$ atom site $(3 c$ sites; $0,1 / 2,1 / 2)$ keeping other atomic positions to the reported one. The calculated profile for this model in Fig. 3 cannot reproduce the observed intensity. In the third model (Model 3), the atomic position of Co in Model 2 was moved from $3 c$ to $6 g$ site; $(6 g: x, 1 / 2,1 / 2)$ as in the case of Cs-GTS. The calculated profile for $x=0.15$ and 0.08 with the site occupancy factor of $1 / 3$ is shown in Fig. 3 . In this case, the increase of 110,111 and 311 peaks has been reproduced qualitatively. It is suggested that $\mathrm{Co}$ atoms occupy the displaced sites from the ring center similarly to the case of Cs-GTS [2].

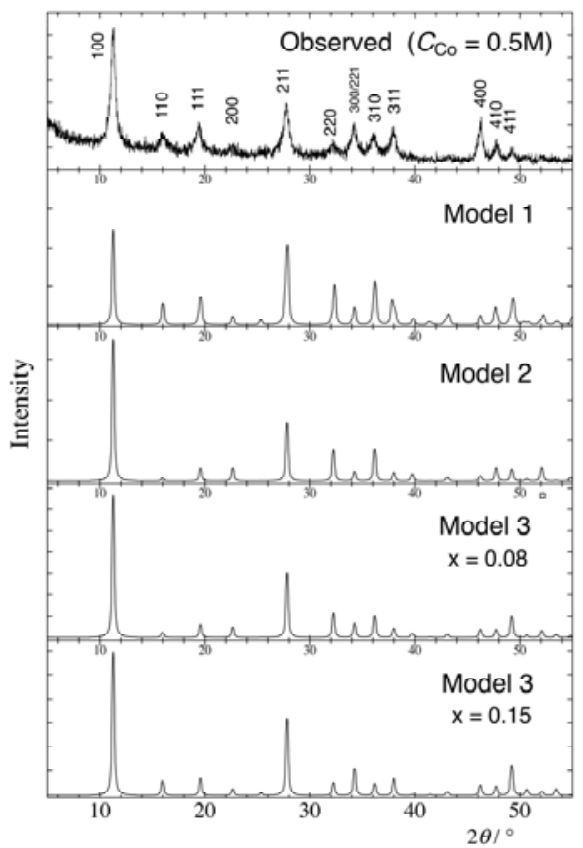

Fig. 3 Calculated XRD patterns of Co-exchanged GTS $\left(\mathrm{Co}_{2} \mathrm{Ti}_{4} \mathrm{Si}_{3} \mathrm{O}_{16} \cdot 4 \mathrm{H}_{2} \mathrm{O}\right)$

Model 1: based on rhombohedral Na-GTS(occupancy 0.5).

Model 2: based on cubic K-GTS : Co atoms are at the face center $3 c$ sites (occupancy 0.6667 ).

Model 3: based on cubic K-GTS: Co site was moved from $3 c$ to $6 g$ site; (6g: $x, 1 / 2,1 / 2), \mathrm{x}=0.08$ and 0.15 (occupancy 0.3333 ).

\subsection{FT-IR and Raman spectra}

Figure 4 shows FT-IR (a) and Raman spectra (b). FT-IR spectra showed apparent change in the absorption peaks due to the $\mathrm{O}-\mathrm{H}$ stretching in the range of 3000 $3600 \mathrm{~cm}^{-1}$ suggesting some change in the hydration state [3]. With increase of Co content, several FT-IR peaks are slightly shifted to higher wavenumbers; for the peak arising from $\mathrm{H}_{2} \mathrm{O}$ bending from 1629 to $1635 \mathrm{~cm}^{-1}$, and for the peaks of Si-O stretching modes from 872 to 880 $\mathrm{cm}^{-1}$. In the Raman spectra, with increase of Co concentration, the peaks of Si-O-Ti stretching mode are shifted from 922 to $944 \mathrm{~cm}^{-1}$, whereas the peaks of Ti-O stretching mode show the inverse shift from 598 to 588 $\mathrm{cm}^{-1}$. The additional peak appearing near $550 \mathrm{~cm}^{-1}$ is probably due to Ti-O-H bonds.

\subsection{TG-DTA}

Figure 5 shows TG and DTA curves of Co-exchanged samples $\left(C_{\mathrm{Co}}=0.025,0.1,0.5\right.$ and $\left.1.0 \mathrm{M}\right)$. DTA curves of the samples kept under the humidity of $13.7 \mathrm{mmHg}$ at $25^{\circ} \mathrm{C}$ show endothermic peaks at 90 and $240 \sim 270^{\circ} \mathrm{C}$. TG curves show $23 \sim 26 \%$ weight decrease up to $300^{\circ} \mathrm{C}$, respectively. With the increase of Co composition, DTA peak temperature is lowered and the water content is slightly increased.

To investigate the origin of DTA peaks, XRD patterns after the TG-DTA measurements were measured. Figure 6(a) and (b) show XRD patterns after the measurements up to 200 and $400^{\circ} \mathrm{C}$, respectively. In the former case, the XRD patterns show peaks of GTS. However, the peak intensities are reduced with the increase of Co composition. When heated up to $400^{\circ} \mathrm{C}$, all the XRD patterns shows amorphous-like patterns. The DTA peak at around $250^{\circ} \mathrm{C}$ is found to be caused from the decomposition of GTS-type titanosilicate due to the complete dehydration.
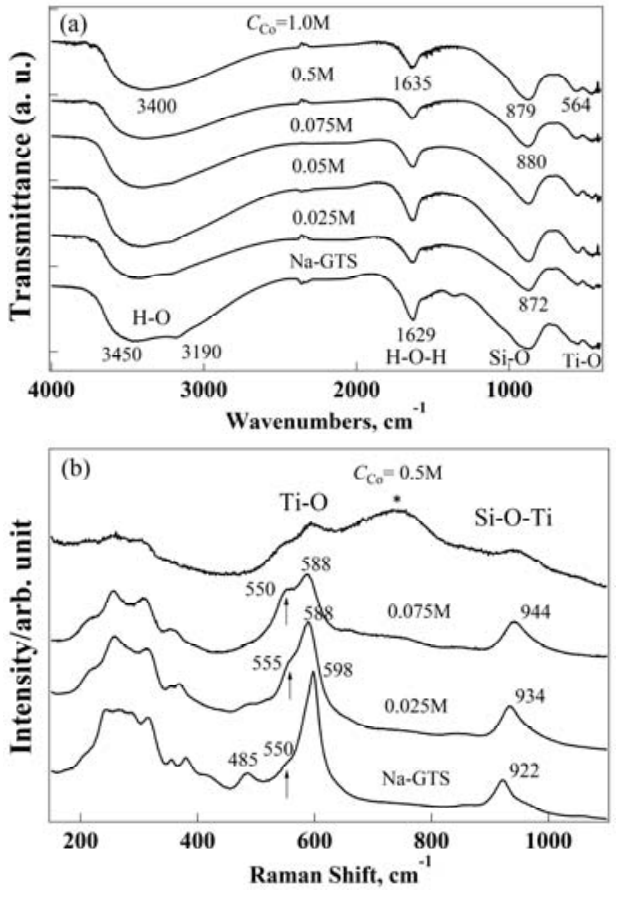

Fig. 4 FT-IR (a) and Raman spectra (b). 
(a)
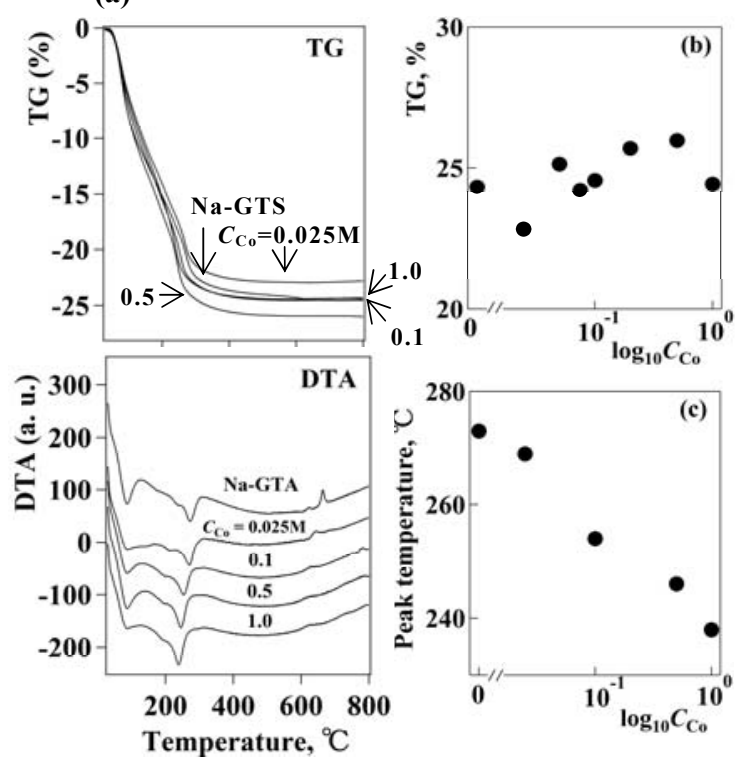

Fig. 5 TG-DTA curves (heating rate: $10^{\circ} \mathrm{C} / \mathrm{min}$ ) of Co-exchanged GTS (a). The water content (b) and the DTA peak temperatures above $200^{\circ} \mathrm{C}$ are plotted in (b) and (c) as a function of logarithmic concentration of $\mathrm{CoCl}_{2}$-aq. solutions.
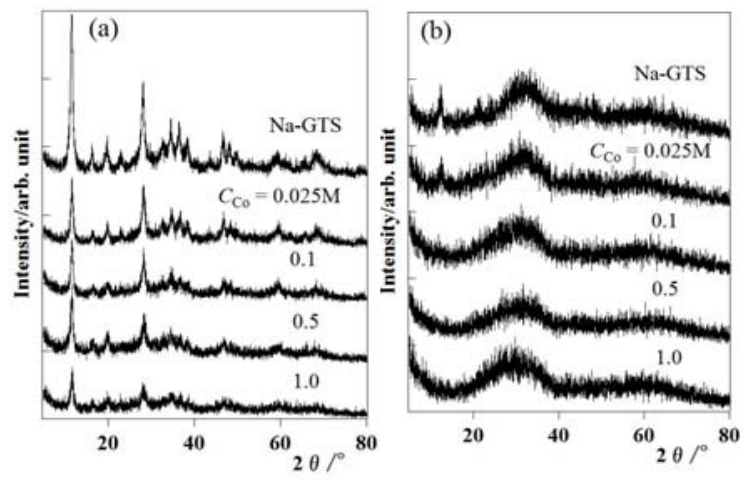

Fig. 6 XRD patterns of the samples heat-treated at 200 (a) and $400^{\circ} \mathrm{C}(\mathrm{b})$. The heating above $400^{\circ} \mathrm{C}$ causes the degradation of crystallinity.

(a)

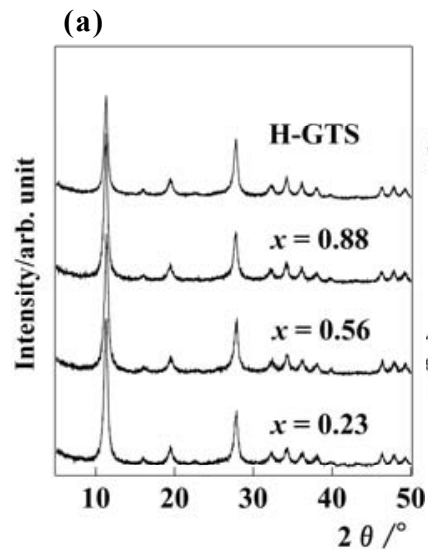

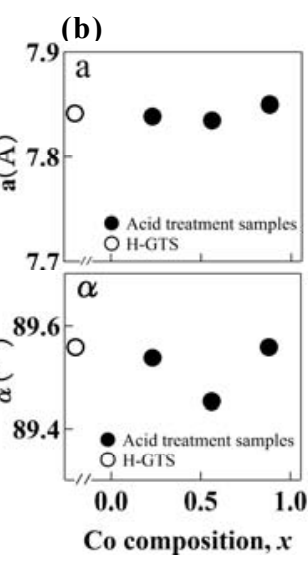

Fig. 7 XRD patterns of Co exchanged GTS samples shaken in $0.1 \mathrm{M} \mathrm{HNO}_{3}$ solution (a) and their rhombohedral lattice parameters (b).
3.5 The elution test by acid solution

Figure 7 shows XRD patterns of Co-exchanged GTS after shaken in the $0.1 \mathrm{M} \mathrm{HNO}_{3}$ solution. The nominal Co composition $x$ in $\mathrm{Na}_{4-4 x} \mathrm{Co}_{2 x} \mathrm{Ti}_{4} \mathrm{Si}_{3} \mathrm{O}_{16}$ of three samples were $0.23,0.56$ and 0.88 , respectively. All the XRD patterns are indexed as cubic GTS. Their lattice parameters and peak intensity ratios are very similar to those of the reported for $\mathrm{H}$ form of GTS [3]. The most of the Co ions were eluted from the GTS and were exchanged by $\mathrm{H}^{+}$ions. The EDTA titration analyses of $\mathrm{Co}^{2+}$ in the eluted solutions indicated that the ratio of $\mathrm{Co}^{2+}$ ions eluted from GTS are 94,93 , and $73 \%$ for $x=$ $0.23,0.56$ and 0.88 , respectively.

\section{CONCLUSION}

Ion-exchange properties of Na-GTS toward $\mathrm{Co}^{2+}$ have been investigated by treating Na-GTS with $\mathrm{CoCl}_{2}$ aqueous solutions $\left(0.025 \leq C_{\mathrm{Co}} \leq 1.0 \mathrm{M}\right)$. Samples with the composition $0.23 \leq x \leq 0.9$ in the formula of $\mathrm{Na}_{4-4 x} \mathrm{Co}_{2 x} \mathrm{Ti}_{4} \mathrm{Si}_{3} \mathrm{O}_{16}$ were obtained. The Co elution ratios were about $90 \%$ for the samples with $x=0.23$ and 0.56 , whereas $70 \%$ for the samples of ion exchange ratio with $x=0.88$. XRD patterns of samples shaken in $0.1 \mathrm{M}$ $\mathrm{HNO}_{3}$ showed the peak intensities ratio similar to the $\mathrm{H}^{+}$-form of GTS. The incorporation of Co into the tunnel sites leads to the cubic GTS-type structure and a slight increase of the lattice parameter. The observed XRD peak intensities indicate that Co atoms occupy the displaced sites in the ring center similarly to the case of Cs-GTS. TG-DTA measurements indicated the increase of water content about $2 \%$ and the slight lowering of dehydration temperature (about $10^{\circ} \mathrm{C}$ ). FT-IR spectra showed apparent change in the absorption peaks due to the O-H stretching in the range of $3000 \sim 3600 \mathrm{~cm}^{-1}$ suggesting some change in the hydration state. The small shifts for the peaks arising from $\mathrm{H}_{2} \mathrm{O}$ bending, $\mathrm{Si}-\mathrm{O}-\mathrm{Ti}$ and Ti-O stretching modes indicate some modification of framework structure by $\mathrm{Co}^{2+}$-exchange.

Acknowledgements

Authors thank Prof. M. Morita and Prof. N. Yoshimoto of Yamaguchi University for the FT-Raman measurements.

\section{REFERENCES}

[1] M. S. Dadachov and W. T. A. Harrison, J. Solid State Chem. 134 (1997) 409.

[2] W. T. Harrison, T. E. Gier, and G. D. Stucky, Zeolites, 15 (1995) 408

[3] E. A. Behrens, D. M. Poojary, and A. Clearfield, Chem. Mater., 8 (1996) 1236.

[4] E. A. Behrens, and A. Clearfield, Micropor. Mater., 11 (1997) 65.

[5] A. M. Puziy, J. Radioanalytical Nuclear Chem. 237 (1998) 73 .

[6] A. Dyer, M. Pillinger, and S. Amin, J. Mater. Chem. 9 (1999) 2481.

[7] V. Kostov-Kytin, S. Ferdov, Yu. Kalvachev, B. Mihailova, and O. Petrov, Micropor. Mesopor. Mater., 105 (2007) 232.

[8] K. Fujiwara, A. Nakatsuka, N. Nakayama, and R. Nikolova, V. Kostov-Kytin, Topics in Chem. and Mater. Sci., 4 (2010) 184.

[9] A. Hioki, N. Fudagawa, M. Kubota, and A. Kawase, Bunseki Kagaku, 38 (1989)149.

(Received December 9, 2012; Accepted June 19, 2013) 